www.jmscr.igmpublication.org

Impact Factor 5.84

Index Copernicus Value: 83.27

ISSN (e)-2347-176x ISSN (p) 2455-0450

crossref DOI: _https://dx.doi.org/10.18535/jmscr/v5i6.179

Journal Of Medical Science And Clinical Research

\title{
The Role of Computed Tomography in the Diagnosis of Pediatric Hydrocephalus
}

\author{
Authors \\ Dr Samrendra Nath Pathak ${ }^{1}$, Dr Ranjeet Kumar Paswan ${ }^{2}$ \\ ${ }^{1}$ Assistant Professor, Department of Radiology, PMCH, Patna \\ ${ }^{2}$ Jr. Resident Department of Radiology, PMCH, Patna
}

\begin{abstract}
Introduction: The introduction of Computed Tomography has major advance role in the diagnosis of Pediatric Hydrocephalus. Despite of improved resolution of the Ultrasound machines exact ventricular assessment is not possible. CT plays an indispensable role in the evaluation of patients with hydrocephalus and in their subsequent management.

Material and Methods: 40 patients were randomly selected in the Department of Radiodiagnosis, Patna Medical College And Hospital, Patna with presenting history of vomiting, fever, impaired consciousness and enlarge head.

Conclusion: This study correlate one common association seen with hydrocephalus, periventricular oedema with various aetiologies of hydrocephalus.

Result: $C T$ is more sensitive in the diagnosis of pediatric hydrocephalus.

Keywords: Hydrocephalus, ventricular dimension, Computerised tomography.
\end{abstract}

\section{INTRODUCTION}

The term Hydrocephalus is derived from Greek word "Hydro" meaning water and "Cephalus" meaning head. It literally means "water in the head" and refers to accumulation of CSF in ventricle with or without similar accumulation in the subarachnoid space.

Plain radiograph finding in hydrocephalus suggest only raised intracranial pressure that present for more than 6 weeks. The sellar changes, sutural distasis, skull vault thickness and optic canal changes are seen mainly on plain radiograph but it doesn't give any clue to the aetiology. Infants with open fontanelle are are examined by sonography but it depends upon skills of examiner and varies from examiner to examiner.
However real time Ultrasound has limited information.

Computed tomography is a new technique that can be reliably identify and localise intracranial abnormalities. It is very helpful in the initial diagnosis and further management of hydrocephalus as well as follow up. Moreover this technique is rapid and non-invasive. This technique localised exact site of obstruction of CSF drainage and their underlying aetiology.

The purpose of present study 'CT' evaluation of hydrocephalus in pediatric age group is to define hydrocephalus with an objective criteria i.e. quantitative assessment of ventricular enlargement, to ascertain the cause of hydrocephalus in different age group. 
Computerised tomography gives more information than only ventricular dimension, it shows ancilliary abnormalities such as focal mass lesion, congenital anomalies of brain, subdural or epidural collection of pus or blood and vascular malformation.

\section{MATERIAL AND METHODS}

The study has been done in the Department of Radiodiagnosis, Patna Medical College, Patna,
India , between March 2016 to April 2017. 40 patients has been reported in the pediatric OPD with enlarge head size presenting with history of fever, vomiting and impaired consciousness were then sent for CT analysis. Consent was taken from all the patients attendant. Patient who already treated or operated for hydrocephalus were excluded from this study.

Indices evaluated in this study are as follows:

1. First Cerebrovascular index:

Maximum distance between tips of anterior horn
Maximum transverse inner diameter of skull along the line of maximum
distance between tips of anterior horn

2. Cella media index ( ratio) :

\section{Maximum transverse biparietal diametr of skull $\overline{\text { Maximum external diameter of lateral ventricle at cella media }}$}

3. Maximum width of third ventricle

G.Hang (1977) performed his study on normal ventricle system taking

into account following linear brain measurement and indices:

a) Maximum inner transverse diameter of skull.

b) Maximum distance of cella media separated only by septum pellucidum.

c) Maximum width of third ventricle.

d) Maximum distance between tips of anterior horn.

Statistical analysis: statistical analysis is done using Microsoft Office 2010. Percentage and mean are used to interpret the result.

\section{DISCUSSION}

Hydrocephalus is an active distension of ventricular system of the brain resulting from inadequate passage from its point of production within cerebral ventricle to its absorption into the systemic circulation.

Because definition requires an active process, it excludes brain atrophy or exvacuo hydrocephalus.
Similarly, because definition requires ventricular distension, it excludes condition in which there is failure of CSF absorption such as pseudotumour cerebri.

Hydrocephalus is classified into communicating and non communicating and their aetiology may be congenital or acquired. The most common congenital cause of hydrocephalus is aqueductal stenosis, Dandy walker malformation, chiari malformation, arachnoid cyst etc and acquired cause is intraventricular haemorrhage, meningitis and brain tumour like medulloblastoma, ependymoma, pilocytic astrocytoma and so on. 


\begin{tabular}{|l|c|c|c|c|c|c|}
\hline Sl.No & $\begin{array}{c}\text { No. Of } \\
\text { patients }\end{array}$ & Age(year) & $1^{\text {st }}$ CVI (mean) & $\begin{array}{c}\text { Cella media } \\
\text { index(mean) }\end{array}$ & $\begin{array}{c}3^{\text {rd }} \text { Ventricle } \\
\text { width(mean) }\end{array}$ & Etiology \\
\hline 1 & 5 & $1-8$ & 46.6 & 2.8 & 11.5 & TBM \\
\hline 2 & 4 & $1-8$ & 58.0 & 2.4 & 18.4 & DWM \\
\hline 3 & 6 & $0-5$ & 56.6 & 2.0 & 21.8 & AS \\
\hline 4 & 6 & $0-2$ & 58.4 & 2.2 & 16.4 & PM \\
\hline 5 & 4 & $1-8$ & 46.2 & 2.8 & 10.6 & IVH \\
\hline 6 & 2 & $0-1$ & 47.0 & 2.6 & 13.2 & EPEN \\
\hline 7 & 2 & $1-8$ & 40.0 & 3.0 & 16.8 & PA \\
\hline 8 & 3 & $1-8$ & 42.1 & 3.2 & 1.4 & MB \\
\hline 9 & 6 & $1-8$ & 54.6 & 2.4 & 13.8 & CC \\
\hline 10 & 2 & $1-8$ & 46.2 & 2.8 & & 10.2 \\
\hline
\end{tabular}

Abbreviation : CVI: cerebrovascular index, CMI: cella media index, TBM : tubercular bacterial meningitis , DWM : Dandy walker malformation, AS : Aqueductal stenosis, I.I. : intrauterine insult, PM : Pyogenic meningitis, IVH : Intraventricular haemorrhage, EPEN: Ependymoma, PA: Pilocytic astrocytoma, MB: Medulloblastoma, CC: Colloid cyst.

The development of CT in assessment of neuroanatomy of brain parenchyma and ventricular system with high precision. The parameter used in my study is mean of cerebrovascular index, mean of cella media index, mean of third ventricle width.

40 Patients are taken in my study, out of which 27 are male and 13 are female child in $3: 1$ ratio. Age group taken between from day of birth to 8 years.

In this study we select 5 patients suffering from tubercular bacterial meningitis and CVI of each patints as 45.4, 46.2, 46.1, 47.1 and 48.2 (mean 46.6), next we calculate CMI of each patients as 3.0, 2.8, 3.2, 2.6 and 2.4 (mean 2.8) and third ventricle width $10.8,11.9,11.1,12.0$ and 11.7 (mean 11.5).

Similarly 4 patients selected with Dandy walker malformation and each of their CVI is 56.4, 58.2, 60.2, 58.2 (mean 58.0), CMI for each patient is 2.7, 2.3, 2.4, 2.2 (mean 2.4) and third ventricle width of each patients 19.2, 17.6, 18.6, 18.2 (mean 18.4).

Six patients develop hydrocephalus due to aqueductal stenosis and their CVI is 58.1, 56.2, 54.5, 58.4, 57.6, 56.6 (mean 56.6) and their CMI 2.2, 2.1, 1.8, 2.0, 1.9, 2.0 (mean 2.0) and third ventricle width $20.8,21.2,19.8,22.3,23.3,23.4$ ( mean 21.8).

Six patients are taken my studies develop hydrocephalus due to congenital intrauterine insult and their CVI measured as 58.2, 59.3, 56.2, $57.5,58.0,61.2$ and mean is $58.4, \mathrm{CMI}$ measured as 2.4, 2.1, 2.0, 2.4, 1.9 and 2.4 ( mean 2.2 ) and third ventricle width as 16.6, 17.2, 18.8, 15.6, 17.0, 16.2 ( mean 16.4 ).

Two patients develop hydrocephaluswith hyperdense lesion within the ventricle suggestive of intraventricular haemorrhage and their CVI measured as 46.8 and 47.2 (mean 47.0), CMI as 2.8, 2.4 mean become 2.6 and $3^{\text {rd }}$ ventricle width 11.8, 11.6 and mean become 13.2.

Four patients presented with fever and seizure, on CECT shows ventricular enlargement with feature of ventriculitis and their CVI calculated as 45.8, 43.2, 50.3, 45.5 (mean 46.2), CMI as 2.6, $2.4,3.0,3.2$ and calculated mean is 2.8 and $3^{\text {rd }}$ ventricle width 11.5, 11.8, 9.8, 9.3 (mean 10.6).

Now thirteen different cases of brain tumour that causes hydrocephalus in children studied separately. CT shows exact location of tumour, their shape and size, density (HU), intra or extra axial location and their enhancement pattern. Most common posterior fossa tumour is medulloblastoma that causes hydrocephalus in 99\% cases, six cases are studied and their CVI calculated as $53.6,52.8,55.1,53.6,54.2,58.3$ ( mean 54.6) and CMI as 2.8, 2.6, 1.9, 2.0, 2.6, 2.5 (mean 2.4) and their third ventricle width as 12.8, $11.9,14.2,13.7,15.2,15.0$ which mean is 13.8 . Two patients of ependymoma (arise from floor of $4^{\text {th }}$ ventricle) having CVI as 38, 42 (mean 40), CMI as 2.8, 3.4 (mean 3.0 ) and $3^{\text {rd }}$ ventricle width 
15.8, 17.8 (mean 16.8). Three patients with pilocytic astrocytoma which is most common childhood tumour than adult and causes ventricular distension, CVI calculated as 39.6, 43.3, 43.2 (mean 42.1), CMI as 3.5, 3.3, 2.8 (mean 3.2) and third ventricle width 12.6, 10.2, 11.4 and calculated mean is 11.4. Two patients with colloid cyst i.e. most common mass found at foramen of monro causes ventricular enlargement and resulting into hydrocephalus, their CVI measured as 45.8, 46.6 ( mean 46.2), CMI as 2.5, 3.1 ( mean 2.8) and their third ventricle width is 10.1 and 10.3 ( mean 10.2).

\section{Periventricular oedema}

In the present study, periventricular oedema was noted in $84 \%$ of cases with hydrocephalus, the incidence varied with different aetiologies of hydrocephalus. Commonest association was seen with inflammatory causes (TBM, Pyogenic meningitis and abscess) with $100 \%$ of cases showing periventricular oedema. Next common association was with tumoral causes. Lesser degree of periventricular oedema even in severe hydrocephalus noted in 0-2 years age group.

Among the various etiologies of hydrocephalus, inflammatory was noted in congenital causes of hydrocephalus.In the present study inflammatory cause (mostly TBM) came out to be most significant (48\%) in the present study. Next most common group was those with congenital causes (24\%) and with tumoral causes (24\%).

\section{RESULT AND CONCLUSION}

Radiograph and USG is a valuable initial modality in patients with hydrocephalus but CT increases the diagnostic confidence. This study correlate one common association seen with hydrocephalus, periventricular oedema with various aetiologies of hydrocephalus.

\section{REFERENCE}

1. BaMc, kpelao ES ,Thioub M, Kouara M, Thiam AB, Ndoye $\mathrm{N}$, etal(post meningitis hydrocephalus in the infants in Dakar) Afr J neuro/ sci-2012;31:8-15.

2. Pomschar A, koerte I, Perand A, Heinenf, Herber jonat $\mathrm{S}$, Reiser $\mathrm{M}$ etal. Hydrocephalus in childhood ; causes and imaging pattern. Radiologue. 2012; 52; 815-20.

3. Vinchon M, Rekate H,Kulkarni A V , pediatric hydrocephalus outcomes: a review fluid barriers CNS. 2012 ;9-18.

4. Dincer A, Ozeak M M.Radiologic evaluation of pediatric hydrocephalus. Child Nervous system.2011; 27;1543-62.

5. Levine $\mathrm{DN}$ : Intracranial pressure \& ventricular expansion in hydrocephalus: Neurol Sci 15 Jun 2008 m 269:1-2:1-11.

6. Harlord LRekate: The definition \& classification of hydrocephalus:a personal recommendation to stimulate debate.CSF. Res 2008:5:2.

7. Adaposn,B D, Lal; Radiologic investigation of normal pressure hydrocephalus, RCNP Vol 13-No.2:353.1978.

8. Harwwol Magh, DC: Paediatric Neuroradiology, RCNA Vol 10, No, 313-335, Aug 1972.

9. Hoare R.D. \& Starnd RD: The third ventricle in hydrocephalus due to basal cistern block, paediatric radiology,2:1521,1974.

10. Lober J \& DE, NG: Family history of congenital hydrocephalus studies in hydrocephalics \& spina bifida. Dev. Med.Child Neuro:22,94,1970.

11. Morei et al, periventricular lucency in hydrocephalus on CT Surg Neurology 8:337-340,1977.

12. Pandya, S.K.;Hydrocephalus, 162-199, in textbook of Neurosurgery of B. Remamurthi, DN Tendon 1980.

13. Babock, D.S, Han, B.K.:The accuracy of high resolution real time ultrasonography of the head in infancy. Radiology, 139-665$676 ; 19$ 